\title{
La Tabula Heracleensis: Organización Municipal
}

\author{
Carmen López-Rendo Rodriguez \\ Professora titular de Direito Romano na Universidade \\ de Oviedo (Espanha)
}

Sumário: 1.Introduccion. 2. Contenido.3. Organizacion administrativa.

Resumen: El trabajo analiza la Tabula Heracleensis recogiéndose los problemas doctrinales nacidos sobre el ámbito de aplicación, época de la misma, así como su identificación o no con la llamada Lex Iulia Municipalis. En el segundo apartado del trabajo se esquematiza el contenido de la misma, finalizando el trabajo con el análisis de las disposiciones normativas que afectan a la organización municipal: a) Magistraturas: clases de magistrados: IVviri y IIviri, Ediles, Cuestores y requisitos para acceder a las magistraturas. b) Senado. c) Censo, analizando el magistrado encargado de su elaboración, plazo, contenido, el procedimiento para enviar los datos a Roma.

Palabras clave: Tabula Heracleensis. Magistrados. IVviri y IIviri. Ediles. Cuestores. Senado. Censo.

\section{INTRODUCCIÓN}

La Tabula Heracleensis ${ }^{1}$ descubierta en $173^{2}$ cerca de Heraclea ${ }^{3}$ en Lucani, ha venido planteando en la doctrina problemas referentes a su ámbito de aplicación: nos encontramos ante una ley de ámbito general o ante una ley particular?, época de la misma, así como su identificación o no con la llamada Lex Iulia Municipalis.

1 V Sobre la Tabula Heracleensis, vid., MAREZOLL, Fragmentum legis romanae in aversa tabulae Heracleensis parte, Göttingen, 1816, SAVIGNY, K. F. «Der römische Volkschluß der Tafel von Herakleia», en Vermischte Schriften, 3, Berlin, 1850 [rptd. Aalen, 1968]. Así como bibliografía citada por LEGRAS, H: La Table Latine d’Heraclée (la prétendue lex Iulia municipalis), Paris, 1907, pp. 383 y ss, sobre las circunstancias de su descubrimiento, pp. 1 y ss. KÜBLER, B.: Recensión a Henri Legras, La Table Latine d'Heraclée (la prétendue lex Iulia municipalis), Paris, Rousseau, 1907. ZSS 28 (1907) pp. 409-415 VON PREMERSTEIN,A en "Die Tafel von Heraclea und die Acta Caesaris". ZSS, 43 (1922), pp 47. Así como la citada por LAMBERTI, F.: Tabulae Irnitanae. Municipalita e Ius Romanorum, Napoli, 1993, p. 203, n. 
1. El primer punto que se discute es si realmente nos encontramos ante una ley general para la organización municipal. La doctrina al respecto ha sostenido opiniones diversas que podemos agrupar en las siguientes corrientes:

a. Defensores del ámbito general. La tesis del ámbito general de la Lex ha sido sostenida por SAVIGNY , que a propósito de la concesión de la ciudadania a la Galia Cisalpina en el año 49, hasta ahora privada de órganos jurisdiccionales autónomos hizo necesaria una ley general que podría ser esta Lex iulia municipalis, a fin de extender a este territorio la organización municipal, permitiendo a los comisarios romanos promulgar leyes útiles para alcanzar la unificación del estatuto municipal.

DE MARTINO ${ }^{5}$ considera que el examen objetivo de la inscripción no consiente la hipotesis de concebirla como una lex data para el municipio de Heraclea. Se decanta por el carácter general de la ley, si bien considera que pudiera discutirse si estamos ante una lex Julia de Cesar que regulase toda la materia municipal o por el contrario es una parte de otra ley.

6. JOHNSON, COLEMAN-NORTON \& BOURNE, Ancient Roman Statutes, Austin, 1961, pp. 93-97, n. 113 . NICOLET, L'Urbs. Espace urbain et histoire, Rome, 1987, pp. 1-25

2 GIRARD, F.-SENN, F: Les lois des Romains. $7^{\mathrm{a}}$ ed. par un groupe de romanistes des "Textes de droit Romain". Tome II. Napoli, 1977, p.148: "Ley latina grabada sobre una de las caras de dos tablas de bronce descubiertas en 1732 y 1734, en dos fragmentos, cerca de Heraclea en Lucani, reunidas en el Museo de Nápoles sobre 1760. La otra cara contiene un texto griego del siglo V concerniente a las propiedades fundiarias de T. De Dyonisios y de T. D’Athena Polias (Dareste- Haussoulier, Inscr. Jur. Grecques I, p. 194.”. ARANGIO RUIZ, V: Historia del Derecho Romano. Madrid, 1994. Trad. Pelsmaecker y otro, p. 255 indica: "Ocupa el reverso de una de las dos grandes tablas de bronce encontradas en el lecho del torrente Salandra (o Cavón) cerca de Pistici en 1732 y proviene, como el anverso (griego) de ambas tablas, de la ciudad de Heraclea, colonia tarentina sita sobre el golfo de igual nombre y después municipio romano. Se conserva en el Museo Nacional de Napoles. Aún cuando se halla entera, la tabla solo contiene una parte (la central) del texto originario". ABASCAL, J.M.- ASPINOSA, U.: La ciudad hispano-romana. Privilegio y poder. Logroño,1989, p. 110, n. 25: "Descubierta en 1732 a ocho millas del emplazamiento de la antigua Heraclea, en Italia: contiene una ley identificada en ocasiones con la lex Iulia municipalis citada en una inscripción de Padua (CIL V 2864= ILS 5406: M. Iunius Sabinus III vir aediliciae potestat. e lege Iulia municipali)".

3 Sobre Heraclea, vid. DE RUGGIERO, E: Dizionario Epigrafico di antichità Romane. II. Roma, 1962, p. 676. "Ciudad de Lucania. Fue Colonia fundada por los Tarentinos en el año 321 a.c (Dio.12,35. Liv. 8.24,4), mas tarde en el 472 o 476 se convierte en aliada de los romanos (Cic. Pro Balbo 22,50; por Archia 4,6) y posteriormente a la guerra social se convierte en municipio (Cic. Pro Archia 4,8 )".

4 SAVIGNY, F.G.: "Der römische Volkschluß der Tafel von Herakleia", Vermischte Schriften, III. Berlín, 1850, pp. 279 y ss. PARETI, L.: Storia di Roma e del mondo romano, IV. Torino, 1955, pp. 330-331.

5 DE MARTINO, F.: “Nota sulla lex Julia municipalis". Diritto e società n'ell antica Roma, Roma, 1979, pp. 342 y 344. 


\section{b. Inexistencia de lex municipalis de ámbito general ${ }^{6}$.}

MOMMSEN $^{7}$ basándose sobre CIL V $2864^{8}$ que se refiere a una lex data ${ }^{9}$ para el estatuto del municipio de Padova, pensó que la lex Iulia fuese precisamente esta lex dictada para el municipio patavino.

VON PREMERSTEIN ${ }^{10}$ sostiene que la Tabula Heracleensis contenía una suma de las Acta Caesaris. Se trataban de una serie de proyectos de ley redactados por Cesar en el 45, y publicados despues de su muerte por Marco Antonio. ${ }^{11}$

2. El segundo de los problemas que se plantea la doctrina es el de la época de la ley. En la actualidad no existe una opinión unánime sobre esta materia. La mayoría

${ }_{6}$ Vid. D’ORS. A.: Epigrafía jurídica, ob. Cit, p. 159. GALSTERER, H.: "La loi municipale des Romains: chimère ou réalite?". Revue historique de droit francais et étranger 65 n 2 2, avr-juin, 1987, pp. 182 y ss. LURASCHI, "Sulle "leges de civitate (Iulia, Calpurnia, Papiria)". SDHI 44 (1978), pp. 325 y ss. MENTXACA, R.: El senado municipal en la Bética. Vitoria-Gasteiz, 1993, pp. 53 y ss.

7 MOMMSEM, TH.: "Lex municipii Tarentini”, Gesammelte Schriften, I, p. 154. En contra TORRENT, A.: La iurisdictio de los magistrados municipales. Salamanca, 1970, p. 164: "Las objeciones a la tesis de Mommsem son muy graves; todo lo mas que podría decirse es que hubo una lex Iulia que disciplinó la fundación de nuevas comunidades, y a esta ley se podría referir la inscripción patavina, pero no hay noticias de una específica lex Iulia para el estatuto municipal de Padova. En el estado actual de fuentes es difícil la identificación de la Tab. Her., pero considero que no es la pretendida ley municipal de reforma general atribuida a Cesar." HARDY, EG: Roman Laws, ob., cit., p. 165 y ss en donde analiza y rebate los argumentos de Mommsen.

8 CIL V 2864= ILS 5406 "M. Iunius Sabinus/ IIIIvir aedili/ciae potestatis/e lege Iulia/ municipali/ patronus/ collegi/ cent/onariorum.."

9 ROTONDI, G.: Leges publicae populi romani: elenco cronológico con una introduzione sull' attività legislativa dei comizi romani, 1966, p. 493 la considera lex data. En la página 4 y ss trata de la lex y sus clases: lex data- lex rogata. En la página 15 indica que las disposiciones por las que se reglamenta la organización de los municipios y colonias revisten la forma de leges datae. D’ORS, A.: Epigrafía jurídica de la España Romana. Madrid, 1953. p. 157. En contra de considerarla como lex data se posiciona DE MARTINO, F.: "Nota sulla lex Julia municipalis". Ob., cit., pp. 342-343. ARANGIO-RUIZ,V. recensión a LEGRAS, DR. HENRI: La table latine d'Heraclée, en BIDR 21(1909), p. 83: "Se trata de una lex Rogata propuesta al pueblo por Cesar dirigida a regular con normas generales el derecho municipal, de ahí el nombre lex Iulia municipalis bajo el que ha sido publicada, citada, comentada por los escritores". La misma opinión se refleja en Historia del Derecho Romano, Ob., cit., pp. 250 y ss. En el mismo sentido de considerarla lex rogata, vid, GIRARD-SENN: Les lois des Romains. Napoli, 1977, p. 74. Sobre lex datalex rogata. Vid. ROTONDI, G: Leges publicae populi romani: elenco cronologico con una introduzione sull' attività legislativa dei comizi romani, 1966, pp. 4 y ss.

10 VON PREMERSTEIN, A: "Die Tafel von Heraclea und die Acta Caesaris". ZSS, 43 (1922), pp. 45.

1 VON PREMERSTEIN, A, ZSS, 43 (1922), ob. cit. pp. 48 y ss, 146, tesis admitida con ciertas reserva por RUDOLPH, H: Stadt und Staat Im römischen Italien. Leipzig, 1935, p. 120. 
de la doctrina ${ }^{12}$, entre los que figuran SAVIGNY, HARDY, PARETI, defienden la postura de datar la misma en la época de Cesar, si bien existen opiniones en contra puestas de relieve por LEGRAS, LONGO, D'ORS ${ }^{13}$.

3. El tercero de los problemas radica en dilucidar si la Tab. Her. se identifica con la lex I ulia municipalis. Esta es la opinión de SAVIGNY, BONFANTE, ARANGIO RUIZ, HARDY ${ }^{14}$. Durante muchos años a la Tabula Heracleensis se la viene llamando lex Iulia municipalis, si bien no existe unanimidad entre la doctrina ${ }^{15}$.

SCHÖNBAUER $^{16}$ piensa que la Tabula Heracleensis no contiene una parte de una lex Iulia municipalis de Cesar del año 45; el texto legislativo es considerado mas antiguo por indicios filológicos y sustanciales. Tampoco la considera como una parte de otra ley municipal general o relativa a muchos municipios. La inscripción no contiene ni siquiera una

12 SAVIGNY, FC: Vermischte Schriften T. III. Ob., cit., p. 337. PARETI, L.: Storia di Roma e del mondo romano, IV. Ob., Cit., pp. 330-332. DE MARTINO, F.: "Nota sulla Lex Iulia municipalis". Ob., cit. pp. 346 y ss. DAREMBERG-SAGLIO: Dictionaire des antiquités grecques et romaines. Graz, 1969. Voz Lex Iulia municipalis, p. 1148: “(A-709=45). Loi proposée par le dictateur César et réglementant l 'administration de la ville de Rome et des municipies". HARDY, EG: Roman Law and charters. Ob., cit., p.137 y ss. GALSTERER, H.: «La loi municipale des Romains: chimère ou realité»?, RHD, 65.2, 1987, 181-203, esp. p. 203

13 LEGRAS, H.: Le table latine. Ob. Cit. niega que se trate de una ley propuesta por Cesar. LONGO. NNDI. P. 823 indica que es difícil admitir que se trate de una lex satura. No se trata de una ley predispuesta por Cesar. D’ORS, A: “Nuevos datos de la Ley Irnitana sobre Jurisdicción municipal”. SDHI 49 (1983), p. 20. ABASCAL, J.M.- ASPINOSA, U.: La ciudad hispano-romana. Privilegio y poder. Logroño,1989, p. 110, n. 25: "Por los datos contenidos en el texto y por su comparación con una pasaje de Cicerón (Ad. Fam. 6,18,1), ha sido identificada tradicionalmente como cesariana supuestamente fechable en el año 45 a.c, aunque hoy la identificación y la cronología carecen de fundamento".

14 SAVIGNY, F.C. Vermischte Schriften III, ob. cit, pp.279 y ss. BONFANTE, P: Storia, II, $3^{\text {a }}$ ed. p. 215. ARANGIO-RUIZ, V: Historia del Derecho Romano. Ob. cit. Pp. 255-256. HARDY, EG: Roman Law and charters. Aalen, 1977, p. 136. PARETI, L: Storia di Roma e del mondo romano, Ob., Cit., p. 331

${ }^{15}$ Cfr. RICCOBONO, S. FIRA. pp. 140-142. Sobre lex Iulia municipalis vid. tambien NAP en Pauly Realencyclopädie der classischen altertumswissenschaft. (En adelante PW) Col. 2368-2389 y la bibliografía mencionada al final en la col. 2389. DE MARTINO, F.: "Nota sulla lex Iulia municipalis". Ob., cit., p. 344: "Tuttavia questa lex Julia non si può confondere con quella contenuta nella tavola di Heraclea, la queales presuppone già tutto l'ordinamento municipale nei suoi organi de è perciò posteriore alla riforma delle magistrature". D’ORS, A.: Epigrafía jurídica, ob., cit., p. 159:" Parece sí evidente que no tenemos una tal lex Iulia municipalis en la Tabla Heraclense". GALSTERER, H: "La loi municipale des Romains: chimère ou réalite?". Revue historique de droit francais et étranger $65 \mathrm{n}^{\circ}$ 2, avr-juin, 1987. ABASCAL, J.MASPINOSA,U.: La ciudad hispano-romana, ob., cit., p. 106 "El documento se atribuyó durante mucho tiempo a Cesar y fue denominado lex Iulia municipalis, aunque hoy sabemos que ninguna de estas dos referencias parece correcta.” TORRENT, A: La Iurisdictio. Ob. Cit., pp. 163-167. D’Ors, A: “Nuevos datos de la Ley Irnitana sobre Jurisdicción municipal”. SDHI 49 (1983), p. 20

${ }^{16}$ SCHÖNBAUER, E.: Die Tafel von Heraclea in neuer Beleuchtung, Anz. Akad. Wien, 1952. pp.109 y ss. En el mismo sentido LONGO, G: NNDI.Torino. p. 823. En contra DE MARTINO, F: "Nota sulla lex Julia municipalis". Diritto e società n'ell antica Roma, Roma, 1979, pp. 342-343. 
lex satura, sino que contenía parte de cinco leyes diversas, probablemente rogatae. Que pueden corresponder al periodo que va entre el 75 y 65, esto es, entre el consulado de C. Aurelio Cotta y las leyes Gabinia y Manilia, y el periodo posterior a la muerte de Sila que se caracteriza por su inspiración política conservadora. Esta cinco leyes según Schönbauer habrían sido puestas juntas formando parte de una lex municipalis Heracleensis, lex data por el comisario romano que venía así a disolver el viejo foedus desde la guerra con Pirro.

$\mathrm{NAP}^{17}$ que considera la Tab. Her. Anterior al Frag. Atrest., cree que sería una colección de leyes presentadas por el tribuno de la plebe C. Papius en el 64 a.c.

TORRENT $^{18}$ indica que la heterogeneidad de las normas depone contra la tesis de una unica lex, considerando dificil la identificación de la Tab. Her. Y que sea la pretendida ley municipal de reforma general atribuida a Cesar

$\mathrm{D}^{\prime} \mathrm{ORS}{ }^{19}$ sostiene que "Augusto dio una ley municipal, y nada impide pensar que se trata de la lex Iulia municipalis, que suele atribuirse a Cesar. La verdad es que esta atribución se había establecido en base a un identificación de esa ley con la Tabula Heracleensis, pero una vez que esta identificación parece hoy equivocada, parece que no hay inconveniente en atribuir esa ley municipal a Augusto y no ya a Cesar". Así para D’ORS ${ }^{20}$ tenemos que rectificar la afirmación muy generalizada de que la lex Iulia municipalis fue una ley de Cesar, pues vemos ahora que fue de Augusto y no de Cesar. Según la opinión de este romanista, tendríamos una ley básica poco posterior al 17 a.C- la lex Iulia municipalis- y un texto reformado de la misma, de quizá el año 90 d.C- lex Flavia municipalis.

Planteado el status quaestionis doctrinal y ante la incertidumbre de sus problemas de orígenes, en el presente estudio me limitaré a destacar el contenido de la Tabula $\mathrm{H}$ eracl eensis en lo referente a la vida municipal tal como nos ha sido transmitido en las fuentes que tenemos a nuestra disposición hasta este momento, a fin de proporcionar las bases para posteriores investigaciones que puedan realizarse en materia.

\section{CONTENIDO}

La Tabula H eracleensis ${ }^{21}$ comprende un conjunto de normas heterogéneas cuyo contenido puede estructurarse a efectos expositivos y siguiendo a DE MARTINO ${ }^{22}$ de la siguiente forma:

17 S NAP, PW, XII,2 (1925) c. 2368-2369.

18 TORRENT, A.: La iurisdictio, ob. cit. pp.164-167.

19 D'ORS, A: "Nuevos datos de la Ley Irnitana sobre Jurisdicción municipal”. SDHI 49 (1983), p. 20. En contra GALSTERER, H.: "La loi municipale", ob., cit., p. 203. MENTXACA, R.: El senado municipal en la Bética. Vitoria-Gasteiz, 1993, pp. 53 y ss.

20 D’ORS, A.: "La nueva copia irnitana de la "Lex flavia municipalis". AHDE Tomo LII, Madrid, 1983, pp. 8-10.

${ }^{21}$ El texto de la Tabula Heracleensis que he utilizado para la elaboración del presente trabajo ha sido el que nos proporciona RICCOBONO, S.: Fontes Ivris Romani antejvstiniani. Pars prima. Leges. Florentiae, 1968, pp. 140-152.

${ }^{22}$ DE MARTINO, F.: "Nota sulla "lex Julia municipalis"”. Diritto e società nell'antica Roma. Roma, 1979, p. 341. 
1. Primera parte -líneas 1-19-, se ocupa de la regulación referente a la distribución gratuita de trigo.

2. La segunda parte que engloba las líneas 20 a la 82 expone las normas que han de regir en materia de conservación, limpieza, libre uso de las vías. Según DE MARTINO $^{23}$ se refieren a la ciudad de Roma, pero son aplicadas a Heraclea mediante la clausula siremps.

3. La tercera y cuarta sección, a la que se refieren las líneas 83 a 158 contienen normas sobre coloniae e praefecturae y regulan las altas magistraturas, del senado y del censo.

4. La última parte de la Tab. Her. que comprende las líneas 159-163 recoge una serie de disposiciones transitorias sobre la virtualidad y cambios de las leyes municipales en los municipia fundana ${ }^{24}$ posteriores al primer año de aplicación de la ley. En ella se permite al encargado de deducir efectivamente la colonia introducir modificaciones en la ley aprobada por los comicios a fin de que el estatuto resultante se adaptara mejor a las necesidades de la comunidad destinataria del mismo.

En el presente trabajo me referiré unicamente a las Disposiciones referidas a la vida municipal.

La Tabula Heracleensis a partir de las líneas 83 en adelante contiene normas que tiene un cierto carácter legislativo y que afectan a la vida municipal. Las mismas se refieren a las Magistraturas, al Senado, al censo, a las fuentes constitutivas del municipio.

El ámbito de aplicación de las disposiciones normativas contenidas en la ley abarca varias categorías de comunidades de ciudadanos romanos, así de forma expresa indica que son válidas para los municipios, colonias, prefectura ${ }^{25}$, foro y conciliabula ${ }^{26}$ Q ueiquomque in municipiès coloneis praefectureis foreis conciliabuleis ciuium R omanorum²7.

${ }^{23}$ DE MARTINO, F.: "Nota sulla "lex Julia municipalis"”. Ob., cit., p. 341, n. 17 indica: "Siempse lex esto: Plaut,. Amph. Prol. 73; Fest., p. 344. V. Siremps. Formazione filologica incerta e discussa: WaldeHoffmann II, 547. Otra Cita en Riccobono, FIRA I,133.n.1."

24 DE MARTINO, F.: "Nota sulla "lex Iulia municipalis", ob. cit., pp. 341-342. "Muncipia fundana erano quelle piccole città italiche, che avevano ottenuto la cittadinanza con la lex Julia e la lex Plautia de avevano decretato costituzionalmente il loro inserimento nella cittadinanza romana".

${ }^{25}$ HARDY, EG: Roman Law and charters. Aalen, 1977. Reprint of the edition Oxford 1911-1912, p. 146 afirma que en el periodo ciceroniano existían esas tres categorías de comunidades, basándose en Cic. Pro Sest. 14.82; Piss. 22.51.BECHARD,F: Droit municipal dans l'antiquite.Paris, 1860.pp 259 y ss.

${ }^{26}$ TORRENT, A: La Iurisdictio. Ob. Cit., p. 65, las concibe como distritos menores, que a su vez 
HARDY ${ }^{28}$ explica de la siguiente forma las diferencias entre ellas: "La extensión de la ciudad de Roma fuera de la ciudad tuvo lugar mediante dos caminos:

A. Algunas veces una número de ciudadanos romanos era enviados a otras ciudades ya existentes o de nueva creación, manteniendo en ambos casos sus derechos como ciudadanos romanos, pero formando distintas comunidades, coloniae. Con el paso del tiempo un gran numero de estas propugnacula imperii, situadas en estratégicos sitios, nacían y muchas de ellas se agrupaban dentro de las mismas categorías por causas sociales.

B. En segundo lugar, Roma frecuentemente conquistaba comunidades que incorpora a su ciudad, pero en este caso los habitantes de estas ciudades eran libres, y quizás nunca plenos ciudadanos romanos. Eran medio ciudadanos, o pasivos ciudadanos, o ciudadanos sine sufragio. Mientras poseían los derechos de comercio, el ius conubium con Roma, pero carecían del jus sufragii o del jus honorum. Ellos eran municipes, es decir, ellos carecían de los privilegios de la civitas. Sus ciudades eran municipia.

Ambas colonias y municipios dependían de la civitas romana, no eran por si mismas civitates y estaban sometidas a la jurisdicción del pretor urbano. Como él no podía ejercer la jurisdicción en persona, cada año nombraba un praefecti iure dicundo, para actuar en representación en estas comunidades.

figuran como núcleos de una división administrativa menor, o como puntos de reunión de los nuevos ciudadanos, terminología que dice venir confirmada en la lex Rubria. Igualmente admite que los fora y conciliabula pueden concebirse como distritos jurisdiccionales a los que iban los praefecti de vez en cuando para administrar in situ justicia. Este romanista reseña que la doctrina tradicional a partir de Mommsen ha considerado que estas comunidades adtributae serían comunidades en las cuales no se había organizado establemente un ordenamiento de tipo cívico, y venían agregadas bajo el perfil administrativo y jurisdiccional a la comunidad principal de la zona, o sea, una colonia o a un municipio, situación que se desarrollaría a partir de la Guerra Social.(...) Quizá bajo este esquema de la adtributio es como deba encuadrase la heterogeneidad de los diversos títulos con los que las leyes municipales mencionan las diversas comunidades sometidas a la nueva reglamentación municipal, que estaría bajo la jurisdicción de los quattuorviri o duoviri de la ciudad dominante."

27 Idéntico elenco de comunidades se encuentra en los fragmentos de la Lex Julia Agraria (Lex mamilia Roscia Peducaea Alliena Fabia). BRUNS. p. 45; GIRARD-SENN P. 70. RICGOBONO. FIRA, Leges., ob., cit., pp. 138 y ss.

${ }^{28}$ HARDY, EG: Roman Law and charters. Aalen, 1977. Reprint of the edition Oxford 1911-1912, pp. 144 y ss. 
Desde este punto de vista, ambos, colonias y municipios tenían la consideración de praefecturae, si bien después de la guerra social todos estos términos eran independientes ${ }^{29}$.

c. F ora y Conciliabula se añadieron a la lista. Estos nombres retornan a la primitiva y pre-urbana organización cantonal, cuando un número de pagi tuvieron algún punto de encuentro central donde las asambleas tribales o el juez tribal tenía su tribunal. Ocasionalmente se refieren a ellos Livio. Considera que se trataban de ciudades rurales dentro del ager romanus, que tenían sus propios negocios locales, pero no reconocidas por la res publicae. Sin duda sobrevivieron por toda Italia y después del 90. B.c. Todas ellas tuvieron la ciudadanía romana. Originalmente dependían de ciudades vecinas si bien fueron intentando conseguir su independencia. Ellos tenían sus propios senadores, tal como se observa en las líneas 83 y 119 de la Tab. Her. Parece ser que carecían de duoviri o quattuorviri y de la posibilidad de elaborar su propio censo, al estar ausentes en las líneas 89 y 108 de la Tab. Her.

Sus magistrados posiblemente fueron solo magistrados, incluidos bajo el aliove quo nomine de la línea 83 de la Tab. Her. Y ciertamente sin jurisdicción. Desde este punto de vista estaban bajo la praefecturae de alguna ciudad vecina”.

\section{ORGANIZACIÓN ADMINISTRATIVA}

La Tabula Heracleensis da una idea aproximada de la organización políticoadministrativa que prevé para todas estas comunidades, en los que los poderes se comparten entre Magistrados, Senado y Asambleas a semejanza de la organización político- republicana.

De la lectura de la misma se observan lo siguientes principios informadores de la reorganización administrativa:

${ }^{29}$ Sobre las distinciones entre colonia y praefectura y sobre municipia y praefectura vid. HARDY, EG:

Roman Law, ob., cit, pp. 144-146. 


\subsection{LAS MAGIST RATURAS.}

\subsubsection{CLASES DE MAGISTRADOS.}

$\mathrm{Al}$ frente de estas comunidades parece ser que se encontraban unas magistraturas típicas que se conocían con el nombre de quattuorvirato o duovirato según las ciudades, los ediles ${ }^{30}$, el cuestor ${ }^{31}$, cuya elección se realizaba libremente en las asambleas populares directamente o por medio de representantes.

La Tabula Heraclensis no indica de forma expresa el magistrado al que se le encomienda la dirección de los comicios, a diferencia de la lex Malacitana en cuyo capítulo $\mathrm{LII}^{32}$ encomienda la misma a duumviri maior natu, ni tampoco regula de forma detallada el procedimiento comicial ${ }^{33}$, que por el contrario si observamos en la Lex Malacitana.

\subsubsection{EL QUATTUORVIRATO34: DUMVIRATO35.}

La ley de forma expresa nada indica respecto a su ámbito de actuación, si bien parece ser por el silencio que a este respecto prestan que esta magistratura no existía en fora y conciliabula.

\footnotetext{
${ }^{30}$ Durante la época de la república los trabajos de conservación de la ciudad en la materia de mantenimiento son competencia de los ediles y sus subordinados: IV viri in urbe purgandis. Sobre los ediles vid. MOMMSEM,T, Compendio del Derecho Público romano. Traducción del alemán por P. Dorado, Madrid, p. 300 y ss. PATTERSON, The magistrates of the Roman republic, Nueva York, 1951; BROUGHTON, The magistrates of the Roman republic, 2 vols, Nueva Cork, 1951-52 y Supplement, Nueva York-Oxford 1960. TORRENT, A, Derecho público romano y sistema de fuentes, Zaragoza, 2002, p. 179 y ss.
}

${ }^{31}$ ABASCAL,JM Y ESPINOSA,U. ob., cit., p. 129: "Duunvirado, edilidad y cuestura constituye, pues el cursus honorum básico en municipios y colonias. No son simples cargos poseedores de funciones delegadas, sino que, a imagen de Roma, son encarnación misma del poder soberano de una ciudadestado, expresión viva de su potestas. Las magistraturas ciudadanas poseen igual categorización jurídica que las de Roma; por eso, su poder tenía que emanar por vía directa de la comunidad ciudadana toda. Estaban sometidas, como las de la Urbe, a los requisitos de temporalidad y colegialidad; esto es debían ser elegidos anualmente por el populus y cada una tenía que ser ejercida de modo pluripersonal (dos o mas personas), formar un colegio magistratual con paridad de status y derecho mutuo de veto entre los componentes (lex Irnit. 27 y lex Salp.27). A las tres magistraturas citadas deben aludir algunas inscripciones cuando indican genéricamente de un personaje "que ha ocupado todos los honores en su res publica". Sobre los magistrados locales, el desarrollo de la organización municipal, su funciones, vid. TORRENT, A.: La iurisdicitio de los magistrados municipales, ob., cit., pp.55 y ss.

${ }^{32}$ Cfr. RICCOBONO, S. FIRA.Leges, ob., cit., p. 210.

33 Vid. TANFANI, L: Contributo alla storia del municipio romano. Roma, 1970, pp.186 y ss.; MENTXACA, R. : El Senado municipal, ob., cit., pp. 73 y ss.

${ }^{34}$ Sobre el origen de esta magistratura, vid DE MARTINO, F.: Storia della costituzione romana. Vol III. Napoli, 1966. p. 298. Manifiesta que esta magistratura fue introducida por Roma. En contra, Vid. ROSENBERG: Der Staat der alten Italiker, München-Berlin, 1914, pp. 45 y ss, sitúa el antecedente 
La imprecisión de los datos que se observan de esta norma ha dado lugar a unas grandes discusiones dentro de la doctrina referente al ámbito de actuación de esta magistratura.

La doctrina de mayor antigüedad ${ }^{36}$ sostiene que en los municipios actuaban los quattuoriviri, mientras que los duoviri su jurisdicción se ceñía a las colonias.

ABASCAL Y ESPINOSA ${ }^{37}$ consideran que "esta diferencia debe tener mas que ver con la época de promoción o con las costumbres locales que con motivos jurídicos, pues ambas magistraturas poseen iguales atribuciones y cumplen idénticas funciones. En algunos casos aparecen las dos en la misma ciudad, fenómeno todavía no explicado satisfactoriamente, aunque tal vez podía deberse a modificaciones del estatuto jurídico".

En cuanto a sus funciones, comparto la opinión de HARDY ${ }^{38}$ de considerar que este supremo órgano judicial combinaba funciones judiciales civiles y penales de un pretor romano con las administrativas de los ediles, así como las palabras de TORRENT ${ }^{39}$ referentes a la autonomía de su jurisdicción a partir de la Guerra Social.

\subsubsection{LOSEDILES}

La Tabula Heracleensis alude a los ediles ${ }^{40} \mathrm{y}$ a sus subordinados IIIIV iri y II viri aedilicia potestate. Con mayor precisión se deducen las competencias de los ediles en

en el octovirato sabino. BERNARDI en la recensión a Dalla monarchia de MAZZARINO en Athen.XXIV (1946), p. 103 considera como precedente los IVviri praefecti Capuam Cumas. Sobre el quattuorvirato y dumvirato, TORRENT, A.: La iurisdictio, ob., cit., pp. 71 y ss.

35 Sobre los Duoviros en las leyes municipales de la Bética, vid. MENTXACA,R: El Senado Municipal en la Bética Hispana a la luz de la Lex Irnitana. Vitoria, 1993, Pp. 70-71

${ }^{36}$ Sobre la relación entre ambos vid. igualmente: GASCOU, J.: "Duumvirat, quattuorvirat et statut dans le cités de Gaule Narbonnaise". Epigrafía. Actes du Colleque international d’epigraphie latine en mémoire de Attilio Degrassi. Roma, 1991. pp. 547 y ss.

37 Sobre las diferentes teorías a favor y en contra, vid. TORRENT, A: La Iurisdictio, ob., cit., pp. 72-80 en donde recoge las tesis de Luzzatto, Beloch, Paserini, Degrassi, Rudolph y su propia opinión.

${ }^{38}$ ABASCAL JM Y ESPINOSA,U. ob. cit. p. 129.

${ }^{39}$ HARDY, EG: ROMAN LAW, ob., cit., pp. 147-148: "No doubt most of the duties of these municipal magistrates were of an aedilician character. But their judicial functions were important. These were both civil and criminal. In both spheres, it was in the last resort subordinate to the supreme jurisdiction of the consuls and praetors, and it was these magistrates who had the right, of course under specified conditions, vocare ex Italia cum quibus lege agi posset. (Tac. Ann. XIII.28)." Sobre la iurisdictio de estos magistrados, vid TORRENT, A: La iurisdictio. Ob. Cit. Pp. 75 y ss.

40 TORRENT, A.: La iurisdictio, ob., cit., pp.75-76: "En términos generales puede concordarse que a partir de la Guerra Social fue ciertamente quattuorvirato o el duovirato según las ciudades el supremo órgano jurisdiccional, jurisdicción que ya no era ejercida como delegada del pretor, como ocurría en los tiempos de los praefecti iure dicundo, sino que era una jurisdicción autónoma." 
materia de distribuciones del trigo, de conservación, limpieza de vías públicas, vigilancia de los usos de los lugares públicos, careciendo de facultades en los que afecta al aspecto económico de cobro y pago, que corresponde a los cuestores.

Durante la época de la república los trabajos de conservación de la ciudad en la materia de mantenimiento son competencia de los ediles ${ }^{41}$ y sus subordinados: IV viri in urbe purgandis, mientras que las decisiones sobre nuevas obras corresponden al censor $^{42}$. Desaparecida la censura tradicional, este servicio se vinculó a la edilidad hasta el principado de Severo Alejandro y desapareció poco después de su muerte en el año 240 d.C.

En la Tabula H eracleensis a los ediles tanto curules como plebeyos, en materia de vialidad, se les encomienda la función de conservación y limpieza de las vías públicas, de ahí la utilización de los verbos: reparar las calles reficere y pavimentar-sternere -vias publicas in urbem Romam, propiusue urbem Romam passus M, reficiundas sternendas:43 limpiar-purgare. ${ }^{44}$

En lo que se refiere a las obligaciones y funciones que impone a la autoridad pública establece que el edil deberá cuidar fundamentalmente:

a. que todos los propietarios que den a una calle que la presente ley les obligue a conservar, lo hagan en cumplimiento de sus instrucciones.

b. que no se estanque el agua en ella, dificultando al pueblo el tránsito por aquella calle.

Para evitar problemas de competencias entre los diferentes ediles dentro de una ciudad, de forma expresa se indica que los ediles tanto curules como plebeyos, en funciones en el momento de dictarse la ley y todos aquellos que después de votada la ley sean designado o creados o tomen posesión del cargo, dentro de los cinco meses siguientes a la

${ }^{41}$ Sobre los ediles, vid. MOMMSEM,T, Compendio del Derecho Público romano. Traducción del alemán por P. Dorado, Madrid, p. 300 y ss. PATTERSON, The magistrates of the Roman republic, Nueva York, 1951; BROUGHTON, The magistrates of the Roman republic, 2 vols, Nueva Cork, 1951-52 y Supplement, Nueva York-Oxford 1960. TORRENT, A, Derecho público romano y sistema de fuentes, Zaragoza, 2002, p. 179 y ss.

${ }^{42}$ Sobre los censores, vid. CANCELLI, Studi sui "censores" e sull "arbitratus" della "lex contractus", Milán 1957. MOMMSEM,T, Compendio del Derecho Público romano. Traducción del alemán por P. Dorado, Madrid, p.291 y ss. SUOLAHTI, The Roman Censors. A study on Social Structure, Helsinki, 1963. TORRENT, A, Derecho público romano y sistema de fuentes, Zaragoza, 2002, p. 170y ss.

${ }^{43}$ Tab. Her. 27 (reficiundas sternendas); 28 (reficiendarum)

${ }_{44}$ Tab. Her. 50 (purgandeis), 51 (purgandeis) (purgandas), 70 (purgandeis) 
elección a dicha magistratura o a su toma de posesión, deben elegir de común acuerdo o a sorteo la parte de la ciudad en la que a cada uno le va a corresponder cuidar de que se reparen y pavimenten las calles dentro de la ciudad y a menos de mil pasos de ella.

A este efecto estarán investidos de poderes que pueden ejercer en todos los lugares que se encuentren dentro de su distrito para ordenar que se realice la reparación y conservación de calles a la que obliga esa ley. Tab. Her.24-2945.

Si el propietario obligado a conservar la vía incumplía su obligación, el edil que tuviera a su cargo la zona podía ejecutar la misma a costa del propietario renuente mediante arriendo del citado servicio a un tercero, en la forma establecida en Tab.Her. 32-50 donde se regula un procedimiento de ejecución forzosa.

Los ediles, los IVviri y IIviri eran los encargados de ordenar la recogida de basuras y despojos diversos-stercus- procedentes de casas y mercados que lo mismo que en la actualidad eran depositados en calles, plazas y edificios públicos, estando a esos efectos investidos de las mismas atribuciones que tenían anteriormente de acuerdo con aquello a que les obligan las leyes, los plebiscitos o senadoconsultos, sin que esta ley derogue nada de lo que ya estaba establecido, tal como se establece en Tab.Her.50-53. ${ }^{46}$

Los ediles y IVviri eran la autoridad pública competente en la ciudad, atribuyéndose la función de la limpieza extramuros de la ciudad de Roma y a menos de mil pasos a los IIviri.

A los ediles y a los magistrados a quienes se encuentra encomendada la limpieza de los lugares públicos de la ciudad de Roma y a menos de mil pasos de la misma, les encomienda la función de vigilancia de los lugares públicos o pórticos públicos ${ }^{47}$ que existen en el momento de dictarse la lex y aquellos que puedan existir en un futuro.

Dentro de estas funciones de vigilancia de forma expresa les impone:

${ }^{45}$ Tab. Her.24-29: Aed(iles) cur(ules) aed(iles) pl(ebei), quei nunc sunt, queiquomque post h. l. r(ogatam) factei createi erunt eumue mag(istratum) inierint, iei in diebus $\mathrm{V}$ proxumeis, | quibus eo mag(istratu) designatei erunt eumue mag(istratum) inierint, inter se paranto aut sortiunto, qua in partei urbis quisque | eorum uias publicas in urbem Romam, propiusue $\mathrm{u}(\mathrm{rbem}) \mathrm{R}(\mathrm{omam})$ passus $\mathrm{M}$, reficiundas sternendas curet, eiusque rei procurationem | habeat. Quae pars quoique aed(ilei) ita h. l. obuenerit, eius aed(ilis) in eis loceis, quae in ea partei erunt, uiarum reficien|darum tuemdarum procuratio esto, utei h. l. oportebit".

46 Tab.Her. 50-53: "Quo minus aed(iles) et IIIIuir(ei) uieis in urbem purgandeis IIuir(ei) uieis extra propiusue urbem Rom(am) passus [M] | purgandeis, queiquomque erunt, uias publicas purgandas curent eiusque rei potestatem habeant, | ita utei legibus pl(ebei)ue sc(itis) s(enatus)[ue] c(onsultis) oportet oportebit, eius h. l. n(ihilum) r(ogatur)".

47 D. 43.8.2.3 Ulpianus libro LXVIII ad edictum indica que Labeón define de que manera se entiende la denominación de lugar publico, de modo que se refiera a los solares, a las casas, a los campos, a las vías publicas y a los caminos públicos. 
A. Impedir la elevación de edificios o construcciones en tales lugares o pórticos.

B. Impedir que se apodere alguien de estos lugares o de algunos de estos pórticos indebidamente.

C. Impedir la instalación de vallas o cierres que hagan difícil al pueblo el acceso a estos pórticos o se lo cierren.

Si bien esta es la regla general, contempla las siguientes excepciones en las que de forma expresa indica que la ley no deroga nada de ello:

a. Casos en los que las leyes, plebiscitos o senadoconsultos otorguen una concesión o permiso a determinadas personas.

b. Lugares que fueron establecidos para el uso y disfrute temporal de arrendamiento de contribuciones o de los mercados de provisiones, como consecuencias de las cláusulas de un contrato establecido ahora en un futuro por el censor u otro magistrado.

c. Celebración de juegos en Roma o a menos de mil pasos de la ciudad de Roma. En este caso se reconoce que existe derecho, como existía anteriormente a erigir estrado, tarima o cuanto sea necesario para tales juegos. Lo mismo que reconoce la existencia de derecho a usar el lugar publico durante su celebración.

d. Los aparitores de los magistrado como sucedía en el pasado podían hacer uso de los lugares públicos en donde les orden establecerse el magistrado al que sirvan.

e. Los lugares cuyo uso y habitación hayan sido concedidos a los esclavos por los censores seguirán destinados para el mismo fin.

\subsubsection{LOS CUESTORES.}

A esta magistratura se refiere el texto de la norma en relación con el aspecto económico derivado del sistema de ejecución forzosa establecido por la ley en materia de conservación de las vías públicas, atribuyendo al mismo la competencia para la celebración del contrato de arriendo, para la inscripción en el registro de créditos del estado y para las fases que han de seguirse para el cobro del crédito ${ }^{48}$.

\footnotetext{
48 vid. Tab. Her. 32-50. En Hispania, estos magistrados no aparecen entre los magistrados de Urso instituyéndose esta magistratura en las leyes flavias de la Betica.
} 


\title{
3.1.1.4 REQUISITOS PARAACCEDER A LAS MAGIST RATURAS
}

El texto de la tabla que hace referencia a estos requisitos es el siguiente:

\begin{abstract}
"Q uei minor annos XXX natus est erit, nei quis eorum post $k$. ianuar. secundas in municipio colonia praefe ctura II uir(atum) III I uir(atum) neue quem ali um mag( istratum) petito neue capito neue gerito, nisei quei eorum stipendia | equo in legione III, aut pedestria in legione VI fecerit, quae stipendia in castreis inue prouincia maiorem | partem sui quoiusque anni fecerit, aut bina semestria, quae ei pro singuleis annueis procedere oporteat, aut ei uocatio rei militaris legibus pl(ebei)ue scitis exuefoidere erit, quocirca eum inueitum merere non oporteat. Neue quis, que praeconium dissignationem libitinamue faciet, dum eorum quid faciet, in municipio colonia praefectura II uir(atum) IIII uir(atum) aliumue quem mag(istratum) petito neue capito neue ger ito neue habeto, | neue ibei senator neue decurio neue conscriptus esto, neue sententiam dicito. Q uei eorum ex eis, quei s(upra) s(criptei) s(unt), I aduersus ea fecerit, is H S ICCC p(opulo) d(are) d(amnas) e(sto), eiusque pecuniaequei uol et petitio esto".
\end{abstract}

La Tabula H eracleensis de forma expresa se refiere en este apartado a los IIviri y III viri o a cualquier otra magistratura de los municipios, colonias o prefectura. En este apartado se observa la omisión de fora o conciliabula, lo que ha llevado a algún sector de la doctrina ha considerar que estas pequeñas ciudades carecían de duoviri o quattuorviri ${ }^{49}$.

Para acceder a las magistraturas se requiere:

1. Una edad mínima que se sitúa en 30 años, reducida en relación con los diferentes periodos de servicios prestados en la legión que varían según si los servicios fueron prestados en caballería o en infantería. Si los servicios en el ejercito fueron prestados en caballería se exige que hubiera participado en tres campañas, mientras que si su participación fue en infantería se le exige seis campañas- nisei quei eorum stipendia equo in legione III, aut pedestria in legione VI fecerit.

2. No ejercer profesión incompatible. Considera como profesiones incompatibles con la magistratura y la pertenencia al senado la de pregonero-praeconium; la de acomodador -dissignatio y la de enterrador-libitina.

Estas circunstancias son causas de incompatibilidad, de tal forma que cuando renuncian a estas profesiones cesan las mismas. En este sentido comparto la opinión de DE MARTINO $^{50}$, quien considera que el ejercicio de la actividad de praeconium y de libitina deben ser actuales -faciet, dum eorum quid faciet. Para ello se fundamenta en:

${ }^{49}$ HARDY, EG :Roman Law, Ob., cit., p. 155. n.7

${ }^{50}$ DE MARTINO,F. Ob. Cit., pp. 344-345. 
a. El testimonio de Cicerón en una carta escribiendo a Lepta en en Febrero del año 45 d.G (ad. Fam. 6.18.1) ${ }^{51}$. El orador había recibido una consulta de Seleuco, uno de los familiares de Lepta, a fin de que le informara sobre el tenor de la ley, para determinar si la inelegibilidad derivada de praeconium se refería también al ejercicio pasado de esta actividad. Conforme a las disposiciones de la Tab. Hera. Cicerón respondió que la norma no se refería al pasado, lo que quiere decir que el candidato podía desistir de su actividad de praeconium en cuyo caso el obstáculo desaparecía.

b. El tenor literal del texto- líneas 94 y ss-, en el que los verbos indican la actividad presente frente a otras partes de la ley, donde se usan expresiones características fecit, fecerit; est, erit; fuit, fuerit para indicar la actividad pasada, presente o futura.

\subsection{EL SENADO}

Los principios mas destacables de la reorganización del senado local que se observan de la ley pueden sintetizarse en los siguientes:

a. Para designar al senado local se emplea reiteradamente el término senatus $5^{52}$ y no el de ordo decurionum, sin embargo en la misma ley, para referirse a los componentes de dicha cámara municipal se emplea la locución senator, decurio $0^{53}$, conscriptus ${ }^{54}$ en diversas variables ${ }^{55}$.

b. Generalización en todas las comunidades del sistema de la lectio magistratual, que ya estaba en vigor en las ciudades de fundación romana. La elección de decuriones o conscriptos la debían realizar los magistrados supremos.

${ }^{51}$ H Cfr. Cic. Ad fam. 6. 18. 1.

2 Tab. Her. 86; 105-106; 109; 124-125; 128. 133-134; 136.

${ }^{53}$ MENTXACA, R: El senado municipal, ob., cit., pp. 78-79 analiza el problema interpretativo que se plantea con la locución decurinum conscriptorumve a propósito de la lex irnitana, pero cuyos argumentos sirven para la Lex Julia municipalis. Sobre la significación histórica de la palabra decurión, vid. TANFANI, L.: Contributo alla storia del municipio romano, ob., cit., pp. 207-208. Entre otros, Vid. Tab. Her. 84- 87: quo nomine mag(istratum) potestatemue $\mathrm{su}<\mathrm{f}>$ ragio eorum, quei quoiusque municipi $\{\mathrm{a}\}$ coloniae praefecturae/ for $<\mathrm{i}>$ conciliabuli erunt, habebunt, nei quis eorum que in eo municipio colonia $\{\mathrm{e}\}$ praefectura $\{\mathrm{t}\}<\mathrm{f}>$ oro concilia-/bulo $<\mathrm{in}>$ senatum decuriones conscriptosue legito neue sublegito neue co\{a\}ptato neue recitandos curato/ nisi in demortuei damnateiue locum eiusue quei confessus erit, se senatorem decurionem conscreiptumue/". Tab. Her 96: neue ibei senator neue decurio neue conscriptus esto neue sententiam dicito. Tab. Her. 104-107: neue eum, quei praeconium dissignationem libitina $<\mathrm{m}>\mathrm{ue} /$ faciet, dum eorum quid faciet, IIuir(um) IIIIuir(um), queiue ibei mag(istratus) sit, renuntiato, neue in senatum neue in de-/curionum conscriptorum numero legito sublegito coptato neue sententiam rogato neue dicere neue/ ferre iubeto 
La Tabula Heracleensis utiliza igualmente la terminología legere, sublegere, cooptare, recitandos curare $^{56}$. La utilización de estos términos ha provocado una discusión en la doctrina.

MOMMSEN $^{57}$ sostiene que sublegere hace referencia a la elección de una persona para sustituir a otra, para ocupar su puesto.

DE RUGGIERO ${ }^{58}$ destaca que solo legere y sublegere se refieren a la admisión de los decuriones mientras que cooptare hace referencia a la nominación por el senado.

$\mathrm{D}^{\prime} \mathrm{ORS}^{59}$ resalta: "Es de suponer que la lectio se hiciera de conformidad con la ley Julia municipal, por los quinquennales, cada cinco años, aunque se conserva el nombre cooptatio, junto a lectio, sublectio, adlectio, lo que parece corresponder a una antigua cooptación por los mismos decuriones."

MENTXACA $^{60}$ en relación con las referencias que encuentra en la lex irnitana indica que "los decuriones eran nombrados formalmente (lecti) como tal cuando el

sc(iens) $\mathrm{d}($ olo) $\mathrm{m}($ alo). Tab. Her. 110 y ss: nei quis in eorum quo municipio/ colonia praefectura $<$ foro $>$ conciliabulo $<\mathrm{in}>$ senatu decurionibus conscreipteisque esto, neue quo $<\mathrm{i}>$ ibi in eo ordine/ $\operatorname{sen}\{\operatorname{ten}\}$ temtiam deicere ferre liceto, quei furtei quod $\mathrm{i}<\mathrm{ps}>\mathrm{e}$ fecit fecerit condemnatus pactusue est erit. Tab.Her. 124-127: aduersus ea in municipio colonia praefectura\{ue\} foro conciliabulo <in senatu> decurionibus conscripteisue $<\mathrm{f}>$ uerit/ sentemtiamue dixerit, is (sestertium) (quinquaginta milia) $\mathrm{p}$ (opulo) $\mathrm{d}($ are $) \mathrm{d}$ (amnas) esto, eiusque pecuniae quei uolet petitio esto. vacat/ quoi h(ac) l(ege) in municipio colonia praefectura foro conciliabulo senatorem decurionem conscriptum esse/ inque eo ordine sentemtiam dicere ferre non licebit, nei quis, quei in eo municipio colonia praefectura. Tab. Her 128-131: foro conciliabulo senatum decuriones conscriptos habebit, eum in senatum decuriones conscriptos/ ire iubeto sc(iens) $\mathrm{d}(\mathrm{olo}) \mathrm{m}(\mathrm{alo})$ neue eum ibei sentemtiam rogato neiue dicere neiue ferre iubeto sc(iens) $\mathrm{d}($ olo $) \mathrm{m}(\mathrm{alo})$; neue quis, que $<\mathrm{i}>/$ in eo municipio colonia praefectura foro conciliabulo sufragio eorum <---> maxumam potestatem habebit,/ eorum quem ibei in senatum decuriones conscriptos ire, neue in eo numero esse $\mathrm{n}<\mathrm{e}>$ ue sentemtiam ibei dicere/.

54 Tab. Her. 87-88; 96, 127. Vid. MOMMSEN,TH.: Römisches Staatsrecht, Leipzig, 1887. p. 840, n. 1. defiende que estos términos tanto en la Tabula Heracleensis, como en las leyes salpensana y malacitana son utilizados como sinónimos. TANFANI, L.: Contributo alla storia del municipio romano, ob., cit., pp. 208-210 le parece que cada uno de ellos indica un mismo concepto bajo formas distintas. Con el nombre de senadores se quiere designar los miembros de la curia de la ciudad latina, los cuales al menos aparentemente mantienen una sombra de la antigua soberanía; decuriones son pro el contrario los miembros del consejo administrativo de los municipios y de las colonias, civium romanorum, fundadas por Roma en Italia, y en las provincias, formadas por las que comprendían la administración de la ciudad itálica, que después de la guerras sociales recibían la ciudadanía romana y de la ciudad provincial, que poco a poco venían adquiriendo este derecho. La denominación de conscripti se había probablemente conservado en los municipios con aquel mismo significado que tenía en roma cuando se oponía a patres. Con tal nombre se trataba de distinguir lo consejeros(decuriones) llamados para ocupar los puestos dejados vacantes en el consejo, por causa de muerte, o por expulsión de aquellos que pertenecían a la curia por derecho, nobleza de sangre o por censo."

MENTXACA, R: El senado municipal. Ob. Cit página 82 sugiere la siguiente hipótesis interpretativa. "El término senatores se refiere a los miembros del antiguo órgano de gobierno de la comunidad peregrina y el de decuriones conscriptive a los antiguos magistrados que habrían surgido en esta fase transitoria entre el otorgamiento de la latinidad por Vespasiano y la organización definitiva 
magistrado llevaba a cabo la confección del álbum municipal, en este caso concreto, cuando se oficializaba y regularizaba el senado anterior, es decir, con la entrada en vigor de la ley, que supondría lógicamente confeccionar por primera vez en el municipio dicho album. Sin embargo, el término sublecti se emplearía para designar a aquellos que habían sido nombrados miembros del senado pero de manera individual, es decir, sin esperar a la elección quinquenal, al producirse vacantes puntuales y ser necesario cubrir las mismas para, entre otras cosas, hacer posible la convocatoria de sesiones y la toma de decisiones por existir el número mínimo requerido de senadores para ello".

La Tabula H eradeensis omite explícitamente la periodicidad de esta lectio magistratual.

La doctrina, entre otros $\mathrm{LAFFI}^{61}$ y TANFANI ${ }^{62}$, viene admitiendo comúnmente que son quinquenales, lo que se encuentra ampliamente documentado por la epigrafia y completado con las operaciones del censo que la misma Tab. Her. 142-158 indica tiene lugar cada 5 años en concomitancia con las operaciones del censo que se desarrollan en Roma.

c. El reclutamiento de decuriones se realizaba entre ex-magistrados de tal forma que los requisitos que se requerían para la admisión al ordo valían también para los magistrados, en tanto en cuanto, como se afirma explícitamente en la Tab. Her. 137 a través del ejercicio de una magistratura se accedía al ordo. La recepción de esta norma se observa en la L ex Pompeia ${ }^{63}$.

d. En caso de insuficiencia de ex-magistrados para completar el senado, el magistrado encargado de la lectio reclutaba a otras personas que no habían sido magistrados, y que recibían el nombre de pedanei o pedarii.

del municipio mediante la Ley Flavia, y que a medida que ponían punto y final a su actividad como magistrados iban engrosando el número de componentes del Senado local ya existente." Sobre senadores e conscripti, vid. TANFANI, L.: Contributo alla storia del municipio romano, ob., cit., pp. 208-210. GALEANO DOMÍNGUEZ,A: El Termino conscripti en la epigrafía hispana e italiana: un nuevo acercamiento a su significado. HABIS 30, 1999, pp. 315 ss.

55 MENTXAGA, R: El senado municipal. Ob. Cit. Pp. 80 y ss.

56 Tab. Her. 86-106. Sobre los significados de legere, sublegere, vid HEUMANN, SECKEL: Handlexikon zu den Quellen des römischen Rechts. 10 ed. Graz, 1958. p. 309 y 561..

${ }^{57}$ MOMMSEN, Th: Römisches Staatsrecht.3.2 Ob. Cit., p. 855 n $^{\circ}$ 2. Se fundamenta en fuentes literarias y en D. 50.2.2. pr.

${ }^{58}$ DE RUGGIERO: La patria nel diritto pubblico romano. Roma, 1921, p. 126 y ss.

${ }^{59}$ D’ORS, A.: Epigrafia jurídica de la España romana. Madrid, 1953. p. 147.

${ }^{60}$ MENTXACA, R: El senado Municipal. Ob. Cit. P.84-85.

${ }^{61}$ LAFFI, U: "I senati locali nell'Italia Repubblicana". Les Burgeoisies municipales italiennes aux Iie. Et Ier. Siècles Av. J.C.,Paris-Neaples, 1983, p. 72. considera que la Tab. Heracleensis generalizó en las comunidades de ciudadanos romanos el sistema de la lectio censoria que tenía lugar cada cinco años, en lugar de llevar a cabo la lectio el censor, la efectuaban los magistrados municipales cada cinco años (lectio quinquennalis).

${ }^{62}$ TANFANI, L.: Contributo alla storia del municipio romano, ob., cit., pp. 214 y ss.

${ }^{63}$ Plinio, Epist. X, 79.1. 
e. Para formar parte del senado, los magistrados que habían cumplido su año en el cargo y ya habían adquirido su derecho a entrar en el senado, debían esperar para su nombramiento a la lectio quinquenal. En el intermedio se les admitía a participar en las reuniones del senado únicamente para poder expresar u opinión - ius sententiae dicendae ${ }^{64}$.

f. En cuanto al número de decuriones que formaba parte del senado, la Tabula Heracleensis guarda silencio, sin que se indique un número absoluto válido para todas las comunidades. Cada Estatuto fijaba el número que consideraba para la respectiva comunidad, unas veces eran 100, en otros casos, como Castrimoenium era $30^{65}$.

g. La duración en el cargo de senador parece ser que tenía el carácter de vitalicio. La Tabula Heracleensis ${ }^{66}$ prohibe el nombramiento de nuevos senadores, salvo para los supuestos de fallecimiento o dimisión de los que existían por causas de incompatibilidad -Queiquomque in municipieis coloneis praefectureis foreis conciliabul eis c(ivium) R (omanorum) II vir(ei) IIII vir(ei) erunt aliove quo nomine mag(istratum) potestatemve sufragio eorum, quei quoiusque municipi coloniae praefecturae fori conciliabuli erunt, habebunt: nei quis eorum quem in eo municipio colonia praefectura foro conciliabulo [in] senatum decuriones conscriptosve legito neve subl egito neve coptato neve recitandos curato, nisi in demortuei damnateive locum eiusve, quei confessus erit, se senatorem decurionem conscreiptumve ibei h. l. esse non licere.

h. Se regulan de forma detallada los requisitos que debían poseer los aspirantes al decurionato en la siguiente forma:

I. Como regla general se exige la edad mínima de 30 años, al igual que para las magistraturas. No obstante se admiten excepciones a no tener cumplidos los 30 años, tomando en cuenta los diferentes periodos de servicios prestados en el ejercito como caballero- tres campañas- o en infantería- seis campañas.

II. Se omite la ingenuitas, así como un requisito especial de cualificación censitaria, sin que esté claro si se exigían o no dichas condiciones.

III. Se disponen unas causas de incompatibilidad: que pueden sistematizarse en:

${ }_{54}$ Tab. Her. 96; 106; 110; 125; 127; 129; 131.

${ }^{65}$ ILS 3475. Sobre el álbum de los decuriones vid. TANZANI, L.: Contributo alla storia del municipio romano, ob., cit., pp. 242 y ss.

${ }^{66}$ Tab. Her. 83-88: "Queiquomque in municipieis coloneis praefectureis foreis conciliabuleis civium Romanorum IIvirei IIIIvirei erunt aliove quo nomine magistratum potestatemve sufragio eorum, quei quoiusque municipi coloniae praefecturae fori conciliabuli erunt, habebunt: nei quis eorum quem in eo municipio colonia praefectura foro conciliabulo in senatum decuriones conscriptosve legito neve sublegito neve coptato neve recitandos curato, nisi in demortuei damnateive locum eiusve, quei confessus erit, se senatorem decurionem conscreiptumve ibei h. l. esse non licere". 
III.1 Profesiones Incompatibles: La de Pregonero - P raeconium; Acomodador - D issignatio; Enterrador - Libitina

III.2 Profesiones consideradas indignas como es el caso del delator, el que se dedicaba al lenocidio, el lanista o comediante, el gladiador

Estas profesiones se consideraban indignas o infames haciendo perder al individuo todo derecho a participar en la curia, aunque el que se presentara a candidato, hubiese abandonado su profesión hace algún tiempo.

IV. No haber sido condenado ni civilmente, mediante la declaración de insolvencia ni penalmente

TANFANI $^{67}$ indica que el fundamento de la insolvencia como impedimento para desempeñar el cargo de decurión se encontraba en que el gobierno central quería asegurar que el decurión no viniera a menos en su ámbito privado, ya que la misma conducta podría observarla frente a sus obligaciones públicas- munera patrimonii.

Entre los supuestos enumerados en la Tabula Heracleensis como supuestos de condena penal, se destacan los siguientes:

1. La condena en ciertos juicios privados seguidos como consecuencia de acciones infamantes, como es el caso de la actio fiduciae, pro socio, tutelae, actio mandati, actio iniuriarum.

2. La condena por hurto.

3. Por haber infringido la ley pletoria que sancionaba como reos a los que habían abusado de la inexperiencia de los menores de 25 años.

4. Por juicio público en Roma y en los municipios.

5. Por calumnia o prevaricación.

6. Por penas sufridas durante el servicio militar: degradación etc.

i. Se hace referencia a honores y privilegios que corresponden a los decurione ${ }^{68}$. De forma explícita se refiere el texto normativo en las líneas 133-134 y 137139 al derecho a sentarse en puestos reservados en espectáculos públicos y el derecho a participar en públicos banquetes ${ }^{69}$.

67 TANZANI, L.: Contributo alla storia dell municipio, ob., cit., p. 223.

${ }^{68}$ DUNCAN JONES: The Economy of the Roman Empire.Cambridge, 1982, p. 141 resalta como privilegio el derecho a recibir cuotas mayores en la distribución de donativos- sportulae.

${ }_{69}$ Tab. Hera. 133-139: "non licebit, $\mathrm{n}<\mathrm{e}>$ quis eorum in municipio colonia praefectura foro conciliabulo IIuir(atum) IIIIuir(atum) aliamue/ quam potestatem, ex quo honore in eum ordinem perueniat, petito neue capito; neue quis eorum ludeis,/ cumue gladiatores ibei pugnabunt, in loco senatorio decurionum conscriptorum $\mathrm{sed}<\mathrm{e}>$ to neue $\mathrm{s}<\mathrm{p}>\mathrm{ectato} /$ neue conuiuium publicum is inito; neiue quis, quei aduersus ea creatu $<\mathrm{s}>$ renuntiatu $<\mathrm{s}>$ erit, ibei IIuir IIIIuir". 


\subsection{CENSO}

La tradición romana atribuye a Servio Tulio la elaboración del censo ${ }^{70}$. Los censos se realizaron también en las colonias y los municipios. En algunas provincias estos censos locales se remontan incluso a una época republicana.

El texto normativo ${ }^{71}$, que sienta determinados principios en esta materia es del siguiente tenor:

Quae municipia coloniae praefecturae c(iuium) R(omanorum) in I talia sunt erunt, quei in eis municipies coloness praefectureis maximum mag(istratum) maximamue potestatem ibei habebit tum, cum censor aliusue quis mag(istratus) Romae populi censum aget, is diebus $L X$ proxumeis, quibus sciet Romae censum populi agi, omnium municipium colonorum suorum queique eius praefecturae erunt, q(uei) c(iues) $R$ (omanei) erunt, censum agito, eorumque nomina praenomina, patres aut patronos, tribus, cognomina, et quot annos quisque eorum habet, et rationem pecuniae ex formula census, quae $\mathrm{R}$ omae $\mathrm{ab} e \mathrm{e}$, qui tum censum populi acturus erit, proposita erit, ab iés iurateis accipito; eaque omnia in tabulas publicas sui municipi referunda curato; eosque libros per legatos, quos maior pars decurionum conscriptorum ad eam rem legarei mittei censuerint tum, cum ea res consuleretur, ad eOs, quei Romae censum agent, mittito; curatoque, utei, quom amplius dies LX reliquei erunt, ante quam diem ei, queiquomque $R$ omae censum aget, finem populi censendi faciant, eos adeant librosque eius municipi coloniae praefecturae edant; isque censor, seiue quis al ius mag(istratus) censum populi aget, di ebus $V$ proximeis, quibus legatei éus municipi coloniae praefecturae adi erint, eos libros census, quei ab ieis legateis dabuntur, accipito s(ine) $\mathrm{d}($ olo) $\mathrm{m}(\mathrm{al} 0)$, exque ieis libreis, quae ibei scripta erunt, in tabulas publicas referunda curato, easque tabulas eodem loco, ubei ceterae tabulae publicae erunt, in quibus census populi perscriptus erit, condendas curato. Qui pluribus in municipies coloneis praefectureis domicilium habebit, et is R omae census erit, quo magis in municipio colonia praefectura h. I. censeatur, elius) h. I. n(ihilum) r(ogatur).

Estas disposiciones normativas demuestran que en los municipios, colonias, prefecturas $^{72}$ la función del censo debía ser ejercitada por el magistrado mayor, esto es la máxima magistratura o quien tuviese la mayor potestad, en el momento en que en Roma se haga el censo. A este magistrado se le encomienda la elaboración del mismo en los 60 días siguientes a aquellos en que tuviera noticia que en Roma se había iniciado la elaboración del censo.

70 TITO LIVIO, I,42,4-44. La creación de la censura en el 443 (Tito Livio, IV, 8, 2: ídem hic annus censurae initium fuit, rei a parva origine ortae) se considera como una reacción patricia (STAVELEY, «The Significance of the consular Tribunate». J.R.S., 43, 1953, pág. 30.

71 Tab. Her. 142-158.

72 Tab. Her. 142 y ss. omite entre la lista de comunidades a fora y conciliabula. En este sentido HARDY, EG: Roman Law, Ob., cit., p.160. n. 22, indica que los habitantes de estas pequeñas ciudades eran incluidos en el censo de comunidades vecinas más amplias. Un estudio en profundidad sobre el censo de la Tabula Heracleensis lo realiza LO CASCIO,E: Le profesiones della Tabula Heracleensis e le procedure del censu in età cesariana, Athenaeum 78, 1990, pp.287-317. 
Se detallan las normas para la formación del elenco de personas de la colonia, municipio o prefectura que debían incluirse en el censo, debiendo constar de cada individuo, según la formula del censo que exponga en Roma quien haga en ese momento el censo del pueblo, los siguientes datos:

- el nombre- nomen.

- el praenomen,

- sus padres o patronos,

- la tribu a la que pertenece,

- el cognomen,

- su edad,

- su patrimonio-rationem pecuniae.

La declaración debía hacerse por cada ciudadano bajo juramento.

Todos estos datos se incluían en un registro público de su respectiva comunidadtabulas pública. Las tahulae publicae locales eran, desde luego, necesarias para llevar un registro exacto de las nuevas incorporaciones a la ciudadanía romana.

Igualmente se disciplinaba el procedimiento para enviar estos datos a Roma, lo que se efectuaba por medio de delegados, seleccionados para este propósito por la mayoría de los decuriones o conscripti presentes en la reunión convocada para su selección.

Una vez elegidos, debían hacer llegar los datos a Roma, en donde eran entregados al censor o a otro magistrado que efectuase el censo- seiue quis alius mag(istratus) censum populi aget ${ }^{73}$ - antes de los 60 días de que finalizaran las operaciones del censo que se efectuaban en la capital, para facilitar a los censores inscribir en la lista general también a los ciudadanos de las comunidades itálicas.

Las medidas que la Tabula Heracleensis trataba de imponer tenían por finalidad una coordinada recepción de todos los datos locales en los archivos de la Urbs, incluyendo una fecha límite, a fin de que el Estado pudiese tener una información completa y actualizada de sus recursos humanos y económicos.

De esta forma se conseguía componer el registro general del pueblo romano, en donde cada ciudadano quedaba censado con los datos anteriores más el municipio de residencia, que suponía una novedad que no existía en los censos antiguos.

Como una apreciación más que los censores municipales debían tener en cuenta, la Tabla de Heraclea (líneas 157 ss.) señalaba que cualquier persona que tuviese su

\footnotetext{
3 Tab. Her. 152-156: censum age $<$ nt $>$, finem populi ce $<$ n $>$ sendi faciant, eos adea $<$ nt $>$ librosque eius municipi coloniae praefecturae/ edant; isque censor, seiue quis alius mag(istratus) censum populi aget, diebus (quinque) proxumeis, quibus legatei eius/ municipi coloniae praefecturae adierint, eos libros census, quei ab ieis legateis dabuntur, accipito/s(ine) $\mathrm{d}($ olo $) \mathrm{m}(\mathrm{alo})$; exque ieis libreis quae ibei scripta erunt in tabulas publicas referunda curato, easque tabulas
} 
domicilium en varios municipios, colonias o prefecturas, y que se hubiese registrado como ciudadano romano en el census de Roma, no tenía obligación de inscribirse en el censo de tales comunidades.

De la regulación que en esta materia efectúa la Tabula Heracleensis se observan las siguientes cuestiones:

a) La descentralización del censo, de tal forma que para inscribirse en el censo no es preciso viajar a Roma, pudiendo efectuarse la inscripción en los municipios y colonias, mediante una formula que luego era enviada por delegados a Roma.

b) Los censores no son los únicos magistrados encargados en la elaboración del censo, de tal forma que además de los censores habla de la existencia de otros magistrados que participan en el censo en la misma Roma.

c) la existencia de una fórmula censoria- ex formula census- que se indica se exponga en Roma, quien en ese momento haga el censo del pueblo, cuyo contenido menciona en el mismo texto, en el que indica los datos que deben registrarse en el censo.

d) la referencia al dolo malo en las operaciones del censo.

\section{ATABULA HERACLEENSIS: ORGANIZAÇÃO MUNICIPAL}

Resumo: Este trabalho analisa a Tabula H eracleensis, destacando os problemas enfrentados pela doutrina no âmbito de sua aplicação e na sua identificação com a chamada Lex Iulia M unicipalis. A segunda parte deste trabalho apresenta o conteúdo da Tabula, por meio de esquema. Finaliza-se com a análise das disposições normativas que afetam a organização municipal: a) Magistraturas: classes de magistrados: IVviri y IIviri, Ediles, Cuestores e requisitos para ascender às magistraturas; b) Senado; c) Censo, analisando o magistrado encarregado de sua elaboração, prazo, conteúdo e procedimento para enviar os dados a Roma.

Pallavras-chave: T abula H eraclensis. Magistrados. Edis. Senado. Censo. 